\title{
A arte de Joseph Beuys e a visão de Andreas Huyssen na pós-modernidade
}

\section{The art of Joseph Beuys and vision Andreas Huyssen in postmodernity}

\author{
Eduardo Portanova Barros ${ }^{1}$, Lívia Garcez de Oliveira Padilha ${ }^{2}$
}

\begin{abstract}
Resumo
Este artigo tem como objetivo apresentar reflexões sobre a arte na pós-modernidade - que estimula uma leitura da ambivalência entre técnica e estética - por meio de duas obras "ambientalistas" do artista plástico Joseph Beuys e do olhar crítico, mas de cunho compreensivo, do ensaísta alemão Andreas Huyssen. O enfoque é o paradoxo entre a arte dita culta ou de vanguarda (?) e a sua possível massificação (?). Estas duas expressões - vanguarda e massificação - ainda se sustentam na paisagem pós-moderna? Ou percebe-se um redirecionamento da sensibilidade em direção àquilo que nos toca pela afetividade? Consideramos, por meio da fenomenologia, que se enfrenta, em tempos pós-modernos, um permanente estado de tensionamento artístico, o que estimula uma visão mais relativista do que categórica da cultura no século XXI.
\end{abstract}

Palavras-chave: Arte. Pós-modernidade. Meio Ambiente. Cultura

\begin{abstract}
This article aims do present reflections on art in post-modernity, which encourages a reading of the ambivalence between the technique and aesthetics. We focus the environmentalist work of artist Joseph Beuys and the critical German essayist Andreas Huyssen and the paradoxical thinking of vanguard and mass culture. Is it possible to think like that in a dualist way? Or we can see a shift in sensitivity towards what touches us by affection? We believe, nevertheless, that exists a permanent state of artistic tension which stimulates a more relativistic than categorical culture in the XXI century.
\end{abstract}

Key-words: Arts. Postmodernity. Environment. Culture

\section{Introdução}

O pensador francês Edgar Morin (1991, p. 126) já afirmou, reiteradas vezes, que complexidade é palavra-problema e não palavra-solução: "Seu mérito é denunciar a metafísica da ordem”. Com isso, ele quer dizer que não pode haver, na interpretação que se faz da cultura e da sociedade, uma resposta única, monovalente, linear. Principalmente agora, numa época que, para muitos teóricos, como Michel Maffesoli (2004), entre outros, é pós- moderna. Pós-moderna porque os valores da modernidade, como a segurança no futuro e no contrato social, esfacelaram-se. Pós-moderna porque a sensibilidade é diferente da anterior, quando prevaleceu uma confiança no progresso e no fato de que esse progresso pudesse trazer algum conforto material e, consequentemente, de espírito. Pós-moderna por causa de uma sinergia entre o prémoderno e a tecnologia de ponta. As características desse paradoxo moderno-pós-moderno poderiam se

\footnotetext{
${ }^{1}$ Jornalista, professor, pós-doutorando no Centro de Pesquisa sobre o Atual e o Cotidiano (CEAQ/Sorbonne) e pesquisador do Laboratório de Políticas Culturais no Brasil (LAPCAB/Unisinos) do Programa de Pós-Graduação em Ciências Sociais da Unisinos. Email: eduardoportanova@hotmail.com

${ }^{2}$ Mestre em Ciências Sociais pela Universidade do Vale do Rio dos Sinos - UNISINOS. Email: liviap27@yahoo.com.br
} 
alongar. O que fica, e é sobre o que este artigo se propõe a refletir, é um jogo dialético entre o sentido de arte na modernidade e na pós-modernidade, o que, teoricamente, desestruturaria a noção de arte genuína (no sentido de grande arte).

Esse jogo dialético, também, estimula uma reflexão da ambivalência na questão artística. Normalmente, a dialética pressupõe uma síntese. No entanto, iremos tomar outro rumo. Preferimos compreender esse jogo de forças enquanto tensionamento, aquilo que permanece nesse estado entre uma coisa e outra, sem uma busca pela síntese afirmativa. Inspiramo-nos, nesse sentido, no trabalho do filósofo francês Mikel Dufrenne (2008, p. 240), que sinaliza para uma dialética entre técnica e estética. Esse paradoxo nos remeteria, segundo ele, "para uma função de mediação entre o homem e o mundo" (DUFRENNE, 2008, p. 241). Dufrenne nos habilita, portanto, a considerar o paradoxo - no nosso caso entre vanguarda e massificação como um jogo dialético, sem que, necessariamente, uma das partes anule a outra. Em não se anulando mutuamente, estas forças, que poderíamos também considerar polaridades, acabam dependendo uma da outra, num estado de permanente tensionamento. O tensionamento, ainda, permite uma reflexão de caráter ambivalente, porque não tem a pretensão do corte e da separação dos opostos.

Conforme o ensaísta alemão Andreas Huyssen (1992a, p. 193), professor de Literatura Comparada na Universidade de Columbia, nos Estados Unidos, a arte adquire outro significado na pós-modernidade. "[...] o termo pós-modernismo é realmente, no momento, totalmente adequado"3. Ele se refere ao que chama de "transformação cultural que emerge lentamente nas sociedades ocidentais" (HUYSSEN, 1992a, p. 193 $)^{4}$ : uma dobra na sensibilidade. Ao afirmar isso, Huyssen (1992a) acaba admitindo que, se existe outro significado, o que chamaremos de "dobra", é porque vivemos de outra forma, a pós- moderna. Huyssen percebe, nos Estados Unidos, uma confusão de códigos sobre as tendências pósmodernistas na arte: anti-moderna, eclética ou modernista mesmo? E é precisamente este o ponto sobre o qual ele se debruça - o que se intui por arte e que nos servirá de reflexão neste artigo. Não muito diferentemente de Huyssen, Coelho é um crítico de e $d a$ arte. Para o professor da Universidade de São Paulo e curador do Masp, a arte, em primeiro lugar, não serve para imitar a natureza, e sim expressá-la.

A expressão na arte, diz ele, é mais importante do que a tentativa de copiá-la (COELHO, 2003, p. 129). Estamos falando de uma arte em meio a uma cultura não mais alta, média e baixa? Que sentido há, hoje, em se falar de uma vanguarda artística? A arte, no final das contas, é assunto só para iniciados? A arte só pode ser conjugada no pretérito ou adquire algum significado no momento em que se perdeu o referencial aurático da sua nobreza? Para Dufrenne (2008), a característica de uma obra de arte depende da maneira como ela é observada. Se for como ele afirma, então, nunca existiram movimentos de vanguarda, uma vez que a vanguarda se distinguia pela suposta excelência artística. Tudo dependeria, dessa forma, de um valor atribuído por uma determinada época. Na conjuntura atual, parece não haver mais uma imposição e um universalismo da arte. O que conta, e nisso a leitura fenomenológica de Dufrenne (2008) se aproximaria de uma característica da pós-modernidade, é o que nos atinge e nos estimula pela sensibilidade aberta, e não pela norma estética "autorista" (aquilo que se diz de um autor como sendo um gênio, acima de todos os outros mortais).

\section{Noção de Arte}

Sempre surgem dúvidas ao longo de leituras que tangenciam as temáticas das artes, da cultura e da política. Ora elas se interpõem, ora se afastam. Isso

\footnotetext{
1 “[...] el término 'posmodernismo' es realmente, al menos por ahora, totalmente adecuado" (Tradução nossa).

2 “[...] una transformación cultural que emerge lentamente en las sociedades occidentales" (Tradução nossa).
} 
é próprio de uma sensibilidade relativista como a de Andres Huyssen. Coelho, mais pragmático, afirma: "Cultura é a regra; arte, a exceção" (COELHO, 2008, p. 117). A arte, continua Coelho (2008, p. 117), é vizinha da cultura, "mesmo tendo aproximações entre uma e outra, acabam na zona movediça que de algum modo delimita os territórios de uma e outra". Todavia, o autor destaca que as diferenças entre cultura e arte são hoje mais significativas do que suas semelhanças. Nota-se uma grande correlação entre a diferença que Coelho enfatiza e as noções de modernidade e pós-modernidade. Para ele:

[...] localizar as diferenças quando se está acostumado e acomodado na ideia de que a tônica é sempre dada pelas identidades, pelas igualdades, pela condição de tudo ser igual a tudo, é tarefa árdua. A noção mesma de uma inadequação entre cultura e arte parece um paradoxo. É adequado que assim seja: o paradoxo é próprio da contemporaneidade. Então, em quê, exatamente, a arte se distingue da cultura, contraria o desenho cultural? (COELHO, 2008, p. 117).

Assim, vê-se nesta inadequação um grande debate, pois, para o autor, o pós-moderno (embora ele não o chame assim), este desenho do que se tinha como cultura - e o que se entendia por arte - está mudando. "Vivemos hoje em um mundo no qual sofremos um impacto muito maior da cultura do que da arte. A arte seria uma espécie de ruptura, como dizia Nietzsche, que a via como a nossa "salvação" (BARROS, 2011). A ambivalência é inevitável. Nietzsche (2002, p. 22), por exemplo, apresenta seu livro "A origem da tragédia" como uma tentativa de "considerar a ciência pela ótica do artista e a arte pela ótica da vida”. Porém, nunca se chega a uma conclusão. Em relação à arte na pós-modernidade, Huyssen (1992b) argumenta, em termos gerais, que o momento pósmoderno não apresenta propostas estéticas definidas, nem coerências, tampouco um estilo. Na verdade, o que se vê, segundo ele, são diferentes propostas e estilos que convivem ou se antagonizam formando um ecletismo ou pluralismo artístico. Ao ler o texto de Huyssen, tem-se a impressão de que ele, com bastante cautela, pontua um dos fatores que mais interessam no debate: a implicação da transformação cultural nas artes ao longo do tempo. Parte da premissa de que:
[...] o que parece em um certo nível como a última tendência, auge publicitário, é parte de uma transformação cultural que emerge lentamente... uma mudança da sensibilidade para a qual o termo pósmodernismo é realmente, pelo menos por enquanto, adequado (HUYSSEN, 1992a, p. 20).

Neste âmbito, ele alerta que o "pós", muitas vezes, é visto como continuidade, no sentido de contínuo à modernidade, ou como uma ruptura, também em relação à modernidade. Tudo isto, segundo o autor, sempre é avaliado, em termos positivos ou negativos. Porém, tentar definir o pósmodermo é uma abordagem a ser evitada, uma vez que o próprio termo, ao estabelecer o fenômeno como relacional, nos previne contra este erro (HUYSSEN, 1992b, p. 22). Assim, levando-se em consideração o entendimento destes autores sobre arte e pós-modernidade, buscaremos, aqui, enfatizar, em especial, as artes plásticas, trazendo um relato sobre a vida do artista alemão Joseph Beuys, cuja obra "ajudou a moldar - e segue ampliando - nosso conceito de arte" (MIRANDA; FARKAS, 2010, p. 2). A seguir, pretendemos elaborar uma breve retrospectiva de fatos que marcaram a vida de Beuys, juntamente com as análises de duas de suas obras que serão apresentadas na sequência. O perfil de Beuys se justifica pelo fato de que, conforme Dufrenne (2008, p. 91), “essa presença da obra com o autor, que define o estilo, ao mesmo tempo justifica a singularidade e ilustra a universalidade da essência”. O autor não deixa de ser um indivíduo, mas sua arte se define pela ideia de coletividade na qual ele mesmo, enquanto artista, está inserido.

\section{Joseph Beuys (1921 - 1986)}

Beuys, além de ser um ícone das artes plásticas, foi também um dos participantes da Documenta 7 de Kassel, na Alemanha, exposição sobre a qual Andreas Huyssen escreve no início de sua obra. A citação é bastante breve em um relato que faz sobre a sua visita à exposição de 1982 junto com seu filho. É a partir dali que ele dá início às suas reflexões. Além deste fato, outra inspiração para trabalhar 
com Beuys vem da pesquisa em um catálogo da mostra realizada recentemente no Brasil que tratou exclusivamente das obras do artista. A exposição, que teve curadoria nacional, com Solange Oliveira Farkas, e um curador internacional convidado, Antonio d'Avossa, trouxe ao país um conjunto de mais de 250 obras, dentro de uma ampla programação com vídeos e documentários sobre a trajetória de Beuys no mundo das artes, além de intervenções e outros materiais. Inspirados na crença do artista de que a transformação social é uma grande obra humana - necessariamente coletiva -, os curadores intitulam este apanhado de "Joseph Beuys - A revolução somos nós" (ASSOCIAÇÃO CULTURAL VIDEOBRASIL, 2010a).

Figura 1 - Capa do catálogo da exposição Joseph Beuys - A revolução somos nós (2010). Reprodução.

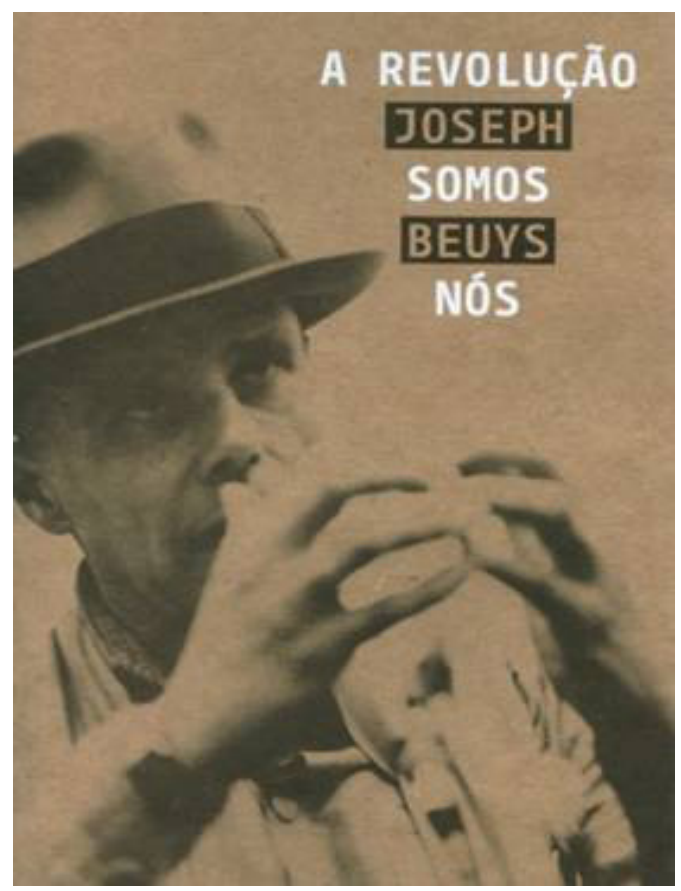

Fonte: Associação Cultural Videobrasil (2010a)

Nascido em Krefeld (Alemanha), Joseph Einrich Beuys manifestou sua decisão pela arte em uma carta endereçada aos pais, em 1943. Todavia, durante um voo sobre posição inimiga, seu avião foi atingido e derrubado. Ferido, Beuys não conseguiu chegar às linhas alemãs e foi coberto por uma tempestade de neve. Encontrado por tártaros, um povo nômade considerado neutro na Guerra, foi resgatado e socorrido. Os tártaros o cobriram de gordura e envolveram-no em feltro, material de que eram feitas suas tendas. Já recuperado, mas ainda vivendo junto aos tártaros, o artista continuou estudando em diversos campos, entre os quais a filosofia, aprimorando-se em esculturas e trabalhando ativamente. Por influência desta passagem tão marcante em sua vida, ele escolheu utilizar, em muitas de suas obras, alguns materiais "energéticos", como feltros e gorduras. Após uma crise depressiva, recuperou-se e começou a trabalhar em seu próprio ateliê de artes. No decorrer de sua vida, Beuys conheceu artistas importantes, como Andy Warhol que, assim como ele, marcaram a arte contemporânea. Expôs em diversos lugares, com destaque para as Documentas de Kassel (3, em 1964; 4, em 1968; 5, em 1972, e 6, em 1977), importantes mostras que se repetem a cada quadriênio. Na sétima documenta, em 1982, expôs o trabalho citado na obra de Huyssen (1992a), uma escultura viva intitulada "7000 Eichen" (7000 Carvalhos).

Figura 2 - Joseph Beuys. 7000 Eichen (7000 carvalhos), 1982. Cartaz. Offset, 60,5 x $85,5 \mathrm{~cm}$.

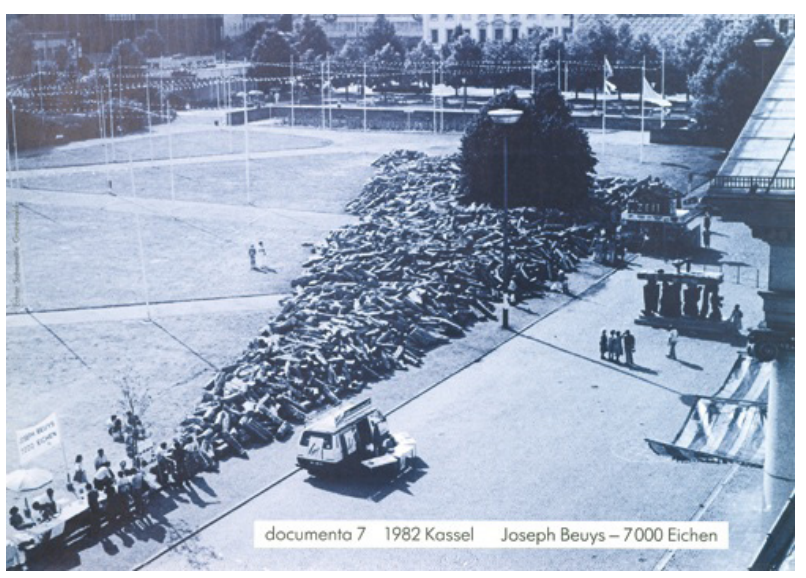

Fonte: Associação Cultural Videobrasil (2010b) 
Nesta obra, a árvore é o principal elemento, pois, segundo Beuys, ela "é regeneradora e carrega um conceito de tempo. O carvalho, em particular, porque cresce lentamente e tem cerne sólido. Sempre foi uma espécie de escultura, um símbolo desse planeta" (BEUYS apud ASSOCIAÇÃO CULTURAL VIDEOBRASIL, 2010b, p. 20). Como explicou Huyssen (1992b, p. 15), a obra do artista era composta por milhares de blocos de basalto, todos arrumados em uma forma triangular, cujo ângulo menor apontava para um carvalho recémplantado. Como um dos participantes do partido ambientalista alemão Os Verdes, Beuys teve um papel importante na fase de fundação do Partido Verde na Alemanha. Nota-se, assim, que, a partir de seu envolvimento na política, sempre buscou trazer em suas obras questões de cunho social e ecológico. Em especial nesta instalação, Beuys faz um apelo aos cidadãos para o cuidado e a importância da natureza (HUYSSEN, 1992b). É interessante destacar que, junto à Documenta 7 , o artista propõe que seja plantadas na cidade de Kassel - reconstruída de concreto após a guerra - uma árvore em cada uma de suas sete mil pedras (HUYSSEN, 1992b, p. 16), totalizando 7 mil árvores plantadas. No Brasil, a importância desta intervenção de Beuys foi tão emblemática que no início da exposição "A revolução somos nós”, em São Paulo, em um ato simbólico e em homenagem ao artista, os curadores e convidados da mostra plantaram sete árvores em frente ao prédio do evento (SSOCIAÇÃO CULTURAL VIDEOBRASIL, 2010b).

\section{"Não Toque! Isso é Arte!"}

A concepção de arte e do pós-modernismo surge no texto de Huyssen (1992a), justamente, quando este cita Beuys. O autor narra que, ao brincar sobre os escombros da obra do artista, seu filho de cinco anos de idade indaga-lhe: “Isso é arte?". E, posteriormente, dentro do museu, novamente ao interagir com outra obra, o menino é advertido por um guarda da exposição, que grita: "Não toque! Isso é arte!". Dentro deste impasse, do que é arte e do que não é, surgem no texto de Huyssen (1992b) referências de uma arte que, assim como Beuys, opta pela originalidade e por analisar criticamente tudo aquilo que se falava como pós-moderno. Nesse momento, o autor e seus leitores se deparam com a seguinte situação: há um grande contraste entre estas obras na Documenta 7. A primeira é viva, integrada ao ambiente, construída ao ar livre, o que permite que seus apreciadores interajam com ela, e até mesmo a transformem. Já a segunda, encontrase "protegida" entre as paredes da galeria, não pode ser tocada, deve ser respeitada, apreciada de longe, permanecendo, assim, imaculada, para que seja admirada como uma relíquia (HUYSSEN, 1992b).

Joseph Beuys, com ações do tipo da Documenta 7 e com o seu compromisso com a democracia, vê claramente na arte um meio de libertar as pessoas; logo, arte, para ele, é a ciência da liberdade. Fica claro que se a arte, alguma vez, teve a ambição do equilíbrio e da harmonia, hoje já não a tem mais (SANTOS, 2009). Beuys consegue, na pluralidade de seus trabalhos, produzir um desequilíbrio, uma certa desarmonia. Conforme afirma Coelho (2005), o artista não é nem porta-voz da informação, nem do saber, ou da realidade, nem da objetividade e do coletivo. Nem de si mesmo, pois o artista contemporâneo, para ele,

[...] é aquele que cria as condições, na obra, para que nela se processe o trabalho específico de sua arte - o trabalho do filme, do romance, da pintura - que, mais do que representar a existência, a põe em ação. A arte contemporânea é esse trabalho, ele próprio uma existência - uma existência maior do que o autor e seu público, razão pela qual esse autor não a controla e não pode usar para transmitir informações, ideias feitas. Porque ele não sabe, antes de fazer a obra, quais serão essas ideias (COELHO, 2005, p.109 grifos originais do autor).

Santos (2009, p. 349) corrobora, dizendo que nem sempre a obra de arte expressamente dotada de um conteúdo político tem necessariamente força política. Para ela, não é preciso "que uma música seja de protesto, para que gere protesto por 
alguma causa política, nem que uma obra teatral seja notadamente engajada, para que sirva como instrumento de educação e conscientização". O interessante no texto da autora supracitada é que, em nenhum momento, ela deixa de citar exemplos e conquistar a atenção para sua ideia. Ela afirma, também, que a perplexidade pode existir, por exemplo, na simples contemplação de um quadro de girassóis, ou seja, ela pode estar tanto no contato com o belo, quanto em uma obra que causa estranhamento e incompreensão (SANTOS, 2009 , p. 352). Talvez, muitas obras como a de Beuys causem estranhamentos, mas, conforme foi visto, a arte e a pós-modernidade se conectam de várias maneiras. Foi a partir dos anos 1960 que esta interação começa a apresentar-se no âmbito mundial. Dessa época, nomes como Marcel Duchamp, o padrinho do pós-modernismo nas artes, Andy Warhol e, é claro, Joseph Beuys são alguns dos artistas lembrados (HUYSSEN, 1992b).

Outro fator relevante neste contexto é que Coelho, como curador de um museu brasileiro importante, o Museu de Arte de São Paulo - MASP, está sempre trabalhando com a ideia de arte em uma sociedade que já não tem os mesmos valores anteriores, e esse é um dilema com que ele se depara. Para Coelho (2008, p. 107), a arte não age em questões sociais, como na exclusão da violência, nem na inclusão social, "como hoje se prefere afirmar num discurso simplista que ostenta tanto um desconhecimento do processo cultural quanto uma vontade de controlar a arte e seus efeitos". A partir desta ideia sobre o "incontrolável", pode-se trazer o pensamento complexo de Edgar Morin (1991). Sendo assim, percebe-se aqui uma situação na qual a ideia sobre a arte, na concepção de Coelho, acaba ficando um pouco distinta do que se entende pela leitura da obra de Beuys, pois este acreditava em uma transformação social através da arte, como mostra uma das suas últimas obras, intitulada Capri-Batterie (Bateria Capri), apresentada em 1985, apenas um ano antes de seu falecimento.
Figura 3 - Joseph Beuys. Capri-Batterie /Bateria Capri, 1985

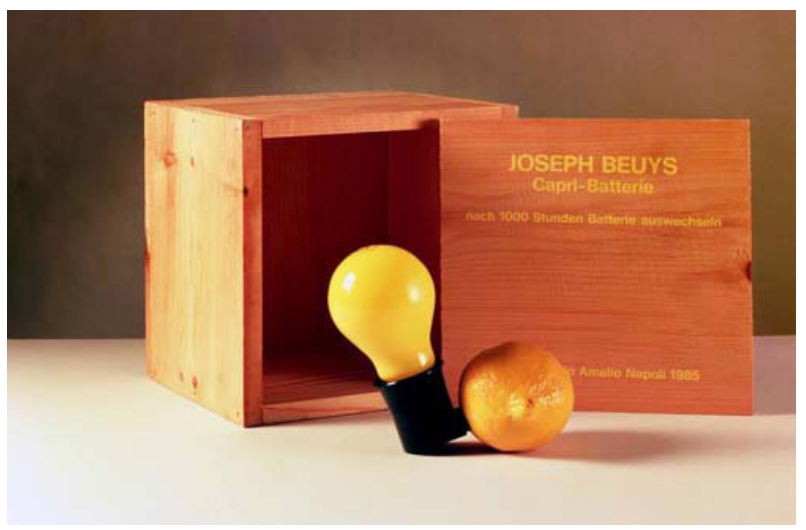

Fonte: ArtArte (2010)

Considerada uma das últimas grandes obras de Beuys - ele criou mais de 200 exemplares de "Baterias Capri”, em 1985 - esta instalação é composta por uma lâmpada amarela que, conectada a um limão, emite um tênue brilho amarelo. $\mathrm{O}$ princípio é o uso da natureza como um recurso de energia sustentável. Ironicamente, as instruções que acompanham a obra diziam: "Trocar bateria a cada mil horas", embora a lâmpada nunca pudesse ser ligada ou desligada de fato (NATIONAL GALLERIES OF SCOTLAND, 2011). O nome da obra vem da Itália, mais especificamente da ilha de Capri, onde Beuys completou este trabalho. Nesse período, o artista estava profundamente envolvido no movimento ambiental alemão. Por isso, seu trabalho procurou desafiar os limites, antecipando, já na década de 1980, algumas questões que hoje são chaves para o mundo, principalmente em termos de sustentabilidade. Assim, percebe-se que, embora existam algumas divergências fundamentais e típicas do período pós-moderno, os textos dos autores trazem ênfases diferentes que complementam a análise das obras de Beuys. Também, concomitante ao debate, percebe-se uma ideia no texto de Coelho (2008) que, talvez, possa ser uma sugestão para ativistas sociais e pessoas envolvidas no meio da transformação social.

É claro o contraste entre a visão de Coelho e a ação de Beuys a respeito das artes. Na pós-modernidade, 
o inusitado é trazido à arte, porque não existe o certo e o errado e as consequências são desconhecidas. Esta subjetividade é perceptível na obra. Tudo é pura falta de controle, até mesmo do próprio artista sobre aquilo que produz. Neste ponto, poderíamos destacar o aspecto autoral em Beuys e nos artistas que se envolvem não só tecnicamente como também umbilicalmente com seu trabalho. Mas como percebê-lo? Para Dufrenne (2008, p. 262), “é quando o artista que se diz verdadeiramente artista nos fala de seu mundo: um mundo que é, de fato, um mundo exterior, mas vivido interiormente, inimitável, ao qual só o sentimento nos dará acesso" Caberia, também, destacar certa contradição existente no discurso de Beuys, um artista contemporâneo, que, de certa forma, estabelece um "efeito" que deseja que suas obras produzam. Assim, algo que pode ser tão pessoal, como as obras criadas por ele poderiam, também, assumir múltiplos sentidos, a partir da visão e da interação com elementos alheios à pessoa que a criou - no caso, o artista.

\section{Um Greenpeace Cultural}

No sentido da política cultural, existem diferenciações entre cultura e arte, conforme foi dito anteriormente. Em um ensaio sobre a "Arte engajada", Coelho (2005, p. 108) afirma que "a questão não é se a arte e seu autor devem participar da discussão pública de seu tempo, comprometer-se ou não com a 'realidade': impossível, quase, evitar uma coisa ou outra”. A questão, para ele, é como se faz isso. Por este viés, podem-se pensar as duas experiências que tiveram as duas obras de Beuys, tanto a referente aos 7000 Eichen, quanto à CapriBatterie. Ambas as obras falam com seu tempo, a primeira ainda mais, uma vez que a Alemanha, na época, já encontrava problemas ambientais e suas florestas estavam sendo destruídas pela chuva ácida (HUYSSEN, 1992b, p. 16). A segunda obra, mais recente, trazia consigo o pensamento de que a energia consumida precisa ter uma fonte - renovável ou não-renovável - e, no caso do limão, esta fonte é um elemento chave, já que se fala de uma fruta que nunca seria cotada como uma possível fonte de energia para uma lâmpada.

Em outro momento, o autor explica que artistas como João Câmara e Salvador Dali, também, o fazem, do único modo ético da arte contemporânea: o da complexidade, criando, assim, espaço para que a perplexidade se instale ali onde não pode deixar de estar (COELHO, 2005). Retoma-se, aqui, um pouco da ideia do complexo, já citado anteriormente no texto, para que se pense como o autor vê e enfatiza a importância de que a arte transpareça e que seja a única autêntica exceção cultural, no momento em que ela se oferece "a quem a faz e a quem a recebe" (COELHO, 2008, p. 105). Para o autor, uma obra de arte faz isso porque não perde o valor autônomo de sua proposição específica, ao não trocá-la ou transformá-la em commodity cambiável (embora a sociedade tente fazê-lo por ela) por qualquer outra científica, política, moral, religiosa, social.

Ao discutir os impasses e os conflitos na arte, um dos itens necessários, na opinião de Coelho (2008), é nos organizarmos. Isto é, organizar os que veem na política cultural um instrumento privilegiado de governabilidade, empoderamento e qualidade de vida. Para o autor, o modelo da Agenda 21, formulado na conferência do Rio em 19925, pode fornecer alguma inspiração neste sentido. É interessante destacar, aqui, que a Agenda 21 se constitui na mais abrangente tentativa já realizada de orientar em direção a um novo padrão de desenvolvimento para o século XXI, cujo alicerce é a sinergia da sustentabilidade ambiental, social e econômica, perpassando todas as suas ações (IIBGE, 2005). Conforme o IBGE, o projeto da Agenda 21 tem um papel fundamental na proposta de ações em favor do desenvolvimento sustentável, elaborado de forma a ser desdobrado em diferentes níveis: global,

${ }^{5}$ Esta Conferência das Nações Unidas sobre o Meio Ambiente e o Desenvolvimento (CNUMAD) também ficou conhecida como Rio-92 ou ECO-92. 
nacional e local (IBGE, 2005). Na ótica da Agenda 21 , todos os atores sociais - mulheres, jovens, ONGs autoridades locais, trabalhadores, empresários, cientistas - "são incitados a participar da tomada de decisão para a construção desse desenvolvimento" (LEROY et al., 2002, p. 17).

Segundo Coelho (2008), o caminho para tais ações é longo e, ainda, estamos atrasados em relação à cultura ecológica. Para ele, isto é tão atual e grave que até exemplifica o tamanho do problema com um caso recente no Texas. Nesse estado norte-americano, na cidade de Austin, para combater a crise orçamentária do Estado, uma ONG de orientação conservadora - Texas Conservative Coalition - propôs uma série de políticas públicas, sendo que uma das ações propostas foi a abolição da Texas Commission on the Arts, o que, para ele, "é uma reforma não apenas de todo irresponsável, como também suicida" (COELHO, 2008, p. 107).

Para irromper novas propostas e não deixar que este tipo de atitude seja cada vez mais presente, o autor acredita que algo análogo à Agenda 21 possa ser pensado para a cultura, uma vez que a cultura ecológica soube dividir seu objeto de reflexão em partes individualizadas bem claras para depois atacá-las sistematicamente. Assim, identificando os campos de intervenção prioritária e agindo neste sentido, Coelho destaca:

[...] essa culturalização de todas as categorias de ver e viver a vida e o mundo, com o instrumento privilegiado que é a arte, poderia assim ser feita a partir de um modelo que escolhesse como prioritários, por exemplo, a educação, a cidade, o divertimento, a representação política e o pensamento econômico (COELHO, 2008, p. 108).

A pós-modernidade, sendo uma nova etapa de evocação do sensível, acaba tornando ineficaz qualquer forma de apreciação crítica, no sentido de distinguir uma obra de arte de um simples produto da cultura. Ou ainda é possível, dentro de alguns pressupostos, estabelecermos critérios para definir um trabalho como sendo ou não de "arte"? Nietzsche (2002, p. 40) percebe uma configuração na arte de estilo instintivo (espírito dionisíaco), de um lado, e racionalista (espírito apolíneo). "Estes dois instintos impulsivos andam lado a lado, até que, por fim, se encontrem para gerarem a obra superior - a tragédia ática”. Mas diz: não se trata de separar uma coisa da outra, porque ambas as tendências estariam em permanente guerra uma com outra. No artista, é isso o que aconteceria, poderíamos afirmar, porque nele existe sempre esta ambivalência entre o racional e o etéreo. E, cada vez mais, interessa menos designarmos um quadro, uma escultura, um filme, uma tela como sendo produto de arte (ou não). Hoje, a palavra "arte" perdeu relevância "aurática”. É ouvida, indiscriminadamente, em todos os meios de comunicação, da televisão ao rádio. Porém, sob a perspectiva crítica, arte ainda é arte. "O objeto estético somente 'assume' e dá o seu sentido através do olhar que o atualiza", afirma Dufrenne (2008, p. 264).

\section{Considerações Finais}

A arte na pós-modernidade apresenta, enfim, uma forma especial, sobretudo a partir da década de 1960, e é nesse período que vários artistas conseguem ganhar espaço. Eles trazem características únicas ao mundo das artes, que colaboram com o entendimento desta grande transformação cultural emergente (HUYSSEN, 1992b). Como visto ao longo do texto, Joseph Beuys é um destes artistas, principalmente ao se vincular com a temática ambientalista, cujo foco emerge como um dos principais assuntos na pós-modernidade, sobretudo, nas questões de caráter ambiental que ganham visibilidade por meio de diversas organizações não governamentais e, em especial, pela atuação do verde na Alemanha e no Brasil, além da radicalidade do grupo midiático sem nenhum demérito - Greenpeace. Beuys, dessa forma, sob este viés ambientalista, está sintonizado com o espírito da pós-modernidade, no qual se sobressaem aspectos como o sensível, o holismo, o tribalismo e o cotidiano, que são os que distinguem uma época da outra. Conforme Barros (2009), é 
Maffesoli que salienta, entre os sociólogos pósmodernos, a contraposição entre pessoa e indivíduo e a temática da pós-modernidade com base na dobra da sensibilidade, no estar-junto (tribalismo) e no cotidiano (vitalismo societal). "Enquanto, para Maffesoli, o indivíduo foi estruturado na modernidade, a pessoa não: emerge em um novo contexto, o de confluência entre o racionalismo progressista e um universo holístico e ecológico" (BARROS, 2009, p. 134). Conforme Coelho (1995, p. 7-8), ainda,

[...] a sensibilidade humana não pode mais ser a mesma e não pode ser estimulada ou atingida pelas propostas que, de um modo ou de outro, puderam ser chamadas de modernas. Surge uma multidão de novos modos estéticos e éticos que pouco ou nada tem em comum com o universo e a sensibilidade da época do romance balzaquiano, da pintura impressionista, do primeiro cinema.

Além de ser considerado "o maior artista alemão do século XX” (MIRANDA; FARKAS, 2010, p. 3), Beuys, ao longo de sua vida, dedicou-se a trabalhar em uma "arte engajada", representando com ela toda a perplexidade e o pluralismo artístico típicos de um tempo em que as incertezas são maiores do que as certezas. Beuys tornou-se um dos expoentes da chamada pós-modernidade e, em suas duas obras que permearam o texto, tais aspectos foram salientados. Juntamente com elas, os textos de Coelho e Andreas Huyssen foram decisivos na tentativa de refletir sobre esta temática, sendo ambos importantes para toda a discussão, embora ainda pudessem ter sido lidos sob outros prismas. É importante não perder de vista o caráter ambíguo e relativista de toda arte, estando-se ou não na pós ou na modernidade. Pelo viés do imaginário, que é a troca entre as pulsões subjetivas e as intimações objetivas do meio (DURAND, 1997), podemos falar, isto sim, de uma imaginação simbólica (artisticamente "superior" ou não, o que não vem ao caso para o imaginário), derivada da inserção física e comportamental da pessoa em contextos historicamente determináveis (COELHO, 1997).
Sendo assim, entende-se que o estudo destes conteúdos seja bastante relevante para a compreensão das formas de interação e de como os problemas contemporâneos, sejam eles de cunho ambiental ou social, estão no âmago da discussão da questão "pós". A partir destas reflexões, percebese que a arte deste modo pode manifestar inúmeras formas, cores, sons, variabilidade de interpretações, reações e relações (SANTOS, 2009) e que, como disse Coelho (2008, p. 139), "a narrativa da obra de cultura conclui; a 'narrativa' da arte não é terminável, permanece inconclusa". Refletindo sobre esta ideia, nota-se que, no que tange à arte na contemporaneidade, talvez possamos imaginála, sim, como "salvação", de acordo com Nietzsche. Talvez, isso ocorra, quando nos permitirmos deixála fazer parte de nossas vidas e nos tornarmos mais artistas. Talvez, devêssemos pensar em Beuys, quando diz: "Todo homem é um artista" (apud ASSOCIAÇÃO CULTURAL VIDEOBRASIL, 2010a, p. 4).

Este é, precisamente, o jogo dialético da pósmodernidade, o de valorizar um modo de ser sensível à complexidade, ao instante eterno e, mais significativo de tudo, integrar as contradições próprias de um sentimento antes trágico, o do artista que não consegue deixar de sê-lo, do que dramático da existência, dramático que procura - sem sucesso - uma resposta cristalina e tranquilizadora ao vivido aqui e agora. A questão que Huyssen coloca é a do tensionamento entre conservação e renovação e entre cultura de massa e de elite. Porém, aquela questão não pode ser vista como categorizações "disto" ou "daquilo", mas antes como apropriações de técnicas e de estéticas, aqui ilustradas pela expressão artística de Beuys, expressão esta ligada a uma conscientização ambiental, mas motivada por um sentimento de autoria como algo que provem de seu interior mais profundo. Assim, leia-se pósmoderno antes como uma reflexão retrospectiva da modernidade do que uma dicotomia que não leve em conta o tecido social no que tem de complexo e, por que não?, contraditório. 


\section{Referências}

ARTARTE. Joseph Beuys. 2010. Disponível em: $<$ http://arteseanp.blogspot.com/2010/10/josephbeuys.html>. Acesso em: 15 jun. 2011.

ASSOCIAÇÃO CULTURAL VIDEOBRASIL. Joseph Beuys: a revolução somos nós. São Paulo: SESC, 2010a.

ASSOCIAÇÃO CULTURAL VIDEOBRASIL. Plantio de 7 quaresmeiras abre Seminário. São Paulo, 20 set. 2010b. Disponível em: <http://www. videobrasil.org.br/blog/?p=1041>. Acesso em: 15 jun. 2011.

BARROS, Eduardo Portanova. O cinema de Ruy Guerra: um imaginário autoral na pós-modernidade. 2009. Tese(Doutorado) - Faculdade dos Meios de Comunicação Social, Pontifícia Universidade Católica do Rio Grande do Sul, Porto Alegre.

A questão pós na Sociologia: o pósestruturalismo, a pós-modernidade e a póscolonialidade. São Leopoldo: UNISINOS, 2011. (Apontamentos de salta de aula no Programa de Pós-Graduação em Ciências Sociais)

COELHO, Teixeira. A cultura e seu contrário: cultura, arte e política pós-2001. São Paulo: Iluminuras: Itaú Cultural, 2008.

Arte engajada: os limites entre a expressão das diferentes visões de mundo e o mero proselitismo - A tradução ignorância. Revista Bravo, São Paulo, ano 8, p. 108-109, jul. 2005.

Dicionário crítico de política cultural: cultura e imaginário. São Paulo: Iluminuras, 1997.

. Entre a vida e a arte. In: BALZAC, Honoré de. A obra-prima ignorada. São Paulo: Comunique, 2003. p. 67-141.

Moderno-pós-moderno. São Paulo: Iluminuras, 1995.

DUFRENNE, Mikel. Estética e filosofia. São Paulo: Perspectiva, 2008.

DURAND, Gilbert. As estruturas antropológicas do imaginário. São Paulo: Martins Fontes, 1997.

HUYSSEN, Andreas. Cartografías del pósmodernismo. In: PICÓ, Josep (Org.). Modernidad y posmodernidad. Madrid: Alianza, 1992a. p. 189241.
. Mapeando o pós-moderno. In: HOLlANDA, Heloísa Buarque (Org.). PósModernismo e política. Rio de Janeiro: Rocco, 1992b. p. 15-80.

IBGE. Perfil dos municípios brasileiros (Meio ambiente - 2002). Rio de Janeiro, 2005. Disponível em: http://www.ibge.gov.br/home/estatistica/ economia/perfilmunic/meio ambiente 2002/ default.shtm. Acesso em: 7 de jun. 2010.

LEROY, Jean-Pierre et al. Tudo ao mesmo tempo agora: desenvolvimento, sustentabilidade, democracia: o que isso tem a ver com você? Petrópolis: RJ: Vozes, 2002.

MAFFESOLI, Michel. Notas sobre a pósmodernidade: o lugar faz o elo. Rio de Janeiro: Atlântica, 2004.

MIRANDA, Danilo Santos de; FARKAS, Solange Oliveira. Estratégias multiplicadas. In: SEMINÁRIO INTERNACIONAL JOSEPH BEUYS: A revolução somos nós, São Paulo, 2010. Anais... São Paulo: SESC, 2010. p. 2-3.

MORIN, Edgar. Introdução ao pensamento complexo. Lisboa: Instituto Piaget, 1991.

NATIONAL GALLERIES OF SCOTLAND. Collection. Disponível em: http://tinyurl.com/ yeondd5. Acesso em 22 de junho de 2011.

NIETZSCHE, Friedrich. A origem da tragédia. São Paulo: Centauro, 2002.

SANTOS, Bianca Caroline dos. Arte como processo cultural - por uma ampliação do humano. Redes. Com, Sevilha, n. 5, p. 341-367, 2009. 